\title{
Use of rare earth oxides as tracers to identify sediment source areas for agricultural hillslopes
}

\author{
C. Deasy and J. N. Quinton \\ Lancaster Environment Centre, Lancaster University, Lancaster, LA1 4YQ, UK \\ Received: 12 May 2010 - Published in Solid Earth Discuss.: 1 July 2010 \\ Revised: 5 November 2010 - Accepted: 20 November 2010 - Published: 26 November 2010
}

\begin{abstract}
Understanding sediment sources is essential to enable more effective targeting of in-field mitigation approaches to reduce diffuse pollution from agricultural land. In this paper we report on the application of rare earth element oxides to arable soils at hillslope scale in order to determine sediment source areas and their relative importance, using a non-intrusive method of surface spraying. Runoff, sediments and rare earth elements lost from four arable hillslope lengths at a site in the UK with clay soils were monitored from three rainfall events after tracer application. Measured erosion rates were low, reflecting the typical event conditions occurring at the site, and less than $1 \%$ of the applied REO tracers were recovered, which is consistent with the results of comparable studies. Tracer recovery at the base of the hillslope was able to indicate the relative importance of different hillslope sediment source areas, which were found to be consistent between events. The principal source of eroded sediments was the upslope area, implying that the wheel tracks were principally conduits for sediment transport, and not highly active sites of erosion. Mitigation treatments for sediment losses from arable hillslopes should therefore focus on methodologies for trapping mobile sediments within wheel track areas through increasing surface roughness or reducing the connectivity of sediment transport processes.
\end{abstract}

\section{Introduction}

Soil erosion from agricultural land is a major source of nutrients in freshwaters (Sharpley et al., 1994; Haygarth and Jarvis, 1999), contributing to eutrophication, and may cause increased turbidity and sedimentation in downstream waters (Owens et al., 2005). Sediment loss from arable land is of

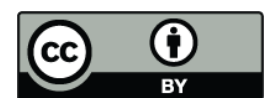

Correspondence to: C. Deasy (c.deasy@lancs.ac.uk) particular concern, as soil is easily eroded from bare and disturbed soil surfaces (Montgomery, 2007).

A number of studies have considered the role of tractor wheel tracks and other tracks and unpaved roads used in many catchments for land management in soil erosion. Recent work (Withers et al., 2006; Li et al., 2007; Tullberg et al., 2007; Deasy et al., 2009b; Silgram et al., 2010) has highlighted the crucial role of tractor wheel tracks and trafficking in surface runoff erosion from arable hillslopes. In the UK, estimates suggest that up to $30 \%$ of sediment transport at catchment scale can originate from roads (Gruszowski et al., 2003), and tracks and unpaved roads in other environments have been shown to contribute significantly to catchment scale sediment transport (MacDonald et al., 1997; Croke et al., 1999; Luce and Black, 2001). Ramos-Scharrón and MacDonald (2005) found that roads can increase sediment production in forested catchments in the eastern Caribbean by up to four orders of magnitude, while a review of relevant literature found that roads can increase sediment loads by up the three orders of magnitude in forested catchments in New Zealand (Fransen et al., 2001). However, most of these studies have taken place using measurements of sediment transport, or using crude tracer techniques, which can only provide estimates of erosion sources.

In any case, on arable hillslopes, questions remain over whether wheel tracks act as source areas or are only transport pathways for sediment eroded from elsewhere in the field. This is because although sediment transfer can be easily observed and measured in runoff pathways, the detachment process itself is difficult to observe and quantify. Understanding the sources of sediment eroded in surface runoff, and their relative importance, is essential to provide data for the development and evaluation of soil erosion and sediment transport models, and enable more effective targeting of in-field mitigation approaches in order to reduce diffuse pollution from agricultural hillslopes. 
Sediment tracers, which allow the movement of eroded soils to be tracked, offer a solution to the problem of determining sediment source areas. The most common field sediment tracing method is now sediment fingerprinting, which relies on the inherent properties of the eroded and source material (Collins and Walling, 2004). Because of the spatial variability of soil properties, sediment fingerprinting is an inappropriate technique where sediment sources and transport need to be defined at high spatial and temporal resolution. We therefore need other techniques to provide short term, spatial data on sediment movement within landscapes.

Artificial tracers can also be used to track eroded soils at smaller time scales. The main limitations of artificial tracers are their differing properties compared to natural material, and the lack of a variety of tracers to determine the spatial dynamics of soil erosion and sediment transport (Zhang et al., 2001). Some applied sediment tracer methods, such as particle labeling of natural soil particles (Olmez et al., 1994) and the mixing of magnetic tracers with soils (Ventura et al., 2001), have proved problematic because of the difficulties of generating and applying such tracers to large field areas. However, a number of recent studies have overcome these limitations through the use of rare earth oxide (REO) tracers.

REOs are oxides available in powder form of the rare earth elements (REEs), the lanthanoid (formerly lanthanide) elements with atomic numbers 57 to 71 . REOs display many of the properties required in a tracer (Zhang et al., 2001), being environmentally benign, and binding strongly to, but also being easily extracted from, the soil. Soils also contain low background concentrations of REEs, which means that large volumes of REO tracers are not required for tracing experiments, and in addition, REO tracers do not require heterogeneous soil physical and chemical properties within a catchment (Kimoto et al., 2006). One of the major benefits of using REOs as tracers is that different REO powders are available which can be applied to different soil areas and used as a spatial tool to trace the movement of sediment. Concentrations of REEs recovered in runoff can then be compared to concentrations of REEs applied as REO tracers and contained in background soil, and can be used to establish the sources and/or rates of erosion. A number of laboratory experiments have been undertaken to determine the applicability of REO tracers and understand the movement of sediment under simulated conditions (Zhang et al., 2001, 2003; Liu et al., 2004; Polyakov and Nearing, 2004; Lei et al., 2006). REOs have also been used in a limited number of studies to understand the movement of sediment in the field (Polyakov et al., 2004; Kimoto et al., 2006; Stevens and Quinton, 2008). Although REOs have become an acceptable method of sediment tracing at sub-catchment scales, it is important to note that this is a relatively new technique, and there are still a number of limitations to the use of REEs as sediment tracers. These include the preferential sorting of the REE tracer in eroded soils, which can also lead to variable behavior of REO tracers under different rainfall conditions (Ventura et al., 2001; Polyakov and Nearing, 2004).

A number of different application methods have been used for previous REO tracer studies, including (i) mixing REO powders with wetted soil and backfilling the soil area with the tracer and soil mix (Zhang et al., 2001), (ii) mixing REO powders with dry soil, undertaking repeated wetting and drying, then spreading on the soil surface and incorporating the mix into the soil (Polyakov et al., 2004), and iii) mixing REO powders with dry soil then spreading the mix on the soil surface using sand to aid even spreading (Stevens and Quinton, 2008). Although direct mixing of REOs with soil has been shown not to substantially change the physicochemical properties of soil aggregates (Zhang et al., 2001), there are differences in the mixing techniques, with direct mixing working best in dry soil (Pryce, 2010). As backfilling is rarely appropriate outside the laboratory (where areas to be tagged with tracer may be large), direct mixing of REO tracer with soil may not be a suitable application method for studies undertaken in the field. Spreading a REO and soil mix on the soil surface may change soil surface properties, particularly where soil pores and crusting have a role in runoff generation and sediment mobilization, and incorporation may be difficult at small scales or on no-till fields. An easy, non-intrusive application method is therefore essential if REO tracing techniques are to be used to understand sediment transport within large field scale experiments.

This aim of this study was therefore to develop a new application method which has advantages over the existing direct mixing methods and which will allow REOs to be applied to large areas without creating disturbance. The method was then applied in the field in order to demonstrate its effectiveness, and to determine the source areas and relative erosion rates for sediment eroded from an arable UK hillslope. This paper presents and discusses the application method and the results of the field study.

\section{Experimental methods}

The REO tracer experiment was undertaken on an arable farm at Loddington, Leicestershire, UK (Fig. 1). Four $1.5 \mathrm{~m}$ wide unbounded hillslope lengths were used for the tracer experiment. All hillslope lengths were cultivated up and down the slope with winter wheat (Triticum aestivum L.), two under minimum tillage, and two under traditional plough cultivation. Each of the hillslope lengths contained a tractor wheel track. Traffic on the hillslope was not limited during this study, as this experiment was undertaken as part of a wider mitigation trial where the farmer was asked to manage the field as if under normal conditions, however, trafficking operations took place in the same way on each hillslope area. There was no difference in ground cover over the hillslope, and this was supported by no recorded difference in yields obtained at harvest time between the different treatments. Hillslope lengths were either $69 \mathrm{~m}$ or $99 \mathrm{~m}$, and were 

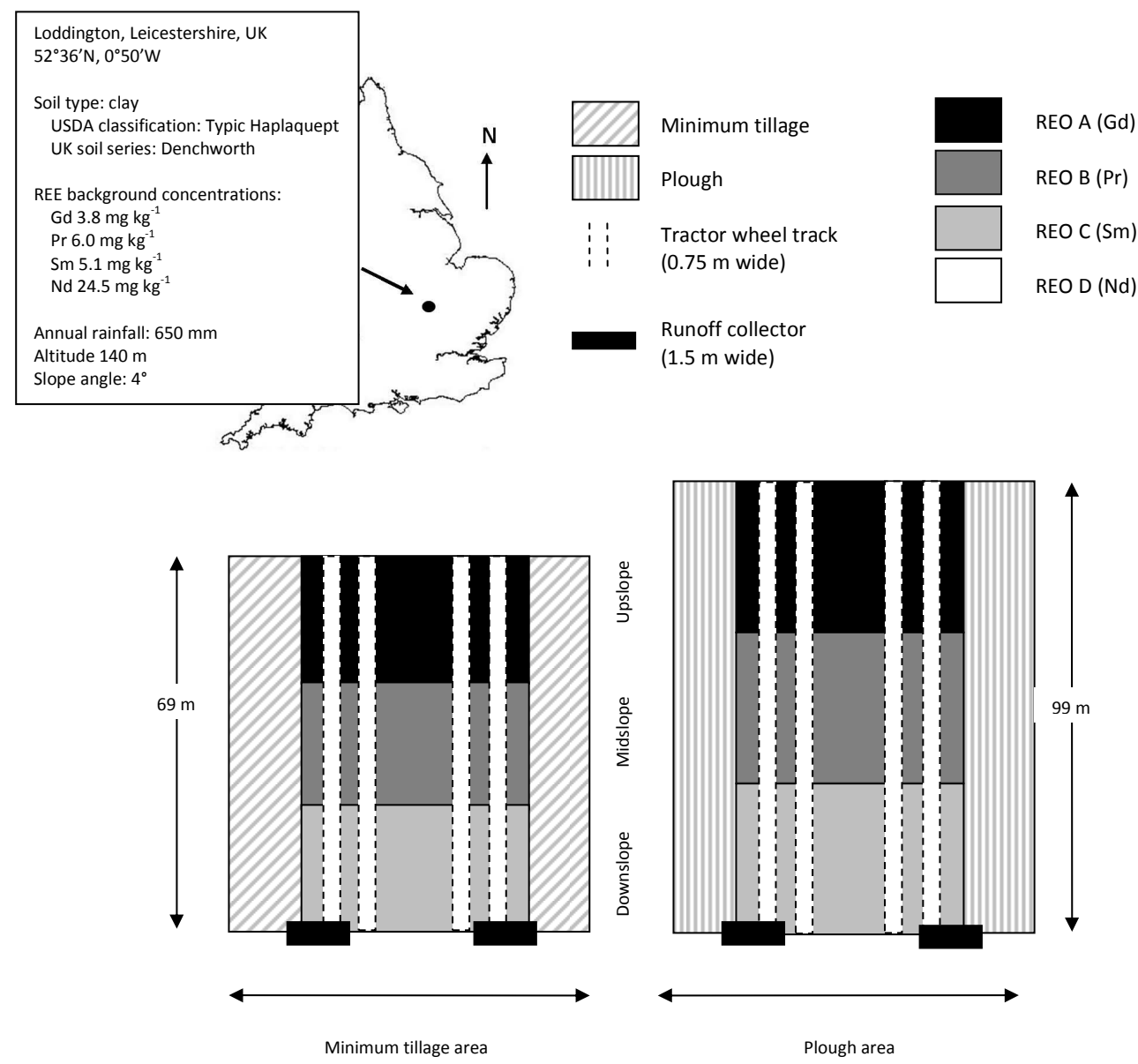

Fig. 1. Location of rare earth oxide (REO) tracer study site, background information and experimental design (not to scale).

longer for the plough areas in order to incorporate all slope elements of concern. The hillslope lengths were split into three areas of interest for hillslope erosion, the topslope, midslope, and downslope hillslope areas, and four different REO tracers $\left(\mathrm{Pr}_{6} \mathrm{O}_{11}, \mathrm{Nd}_{2} \mathrm{O}_{3}, \mathrm{Sm}_{2} \mathrm{O}_{3}\right.$ and $\left.\mathrm{Gd}_{2} \mathrm{O}_{3}\right)$ were applied to these three hillslope segments and to the wheel track areas (Fig. 1). The middle and downslope segments were of uniform slope (approximately $6^{\circ}$ ), while the upslope segments were more convex and slightly shallower (approximately $2^{\circ}$ ). The segment slopes for different monitored hillslope areas were similar. Tracers were applied on 25 January 2008, and were banded across the entire hillslope so that all of the potentially connected hillslope area was tagged with the tracer.

The use of a tracer application method which did not disturb the soil surface was essential for this study as the tracer experiment took place during the third year of a field campaign exploring in-field mitigation options to reduce diffuse pollution losses from arable land to water (Deasy et al., $2009 b$ ). REO powders were applied to the hillslope in suspension in deionised water, using a calibrated manual knapsack sprayer (Allman X15, Allman Sprayers Ltd., Chichester, UK) with a constant pressure valve which allowed an even flow rate for tracer application. The concentration of the applied REO suspension varied depending on the REO, and the length of the hillslope to be sprayed. The approximate ground cover rate was $0.8 \mathrm{~m} \mathrm{~s}^{-1}$, and the calibrated spray rate was $14 \mathrm{ml} \mathrm{s}^{-1}$. The target application rate was 50 times background REE concentration assuming a $1 \mathrm{~cm}$ depth of interaction inferred from previous REO experiments in the laboratory (Stevens and Quinton, 2008). Stevens and Quinton showed in the laboratory that concentrations of REO decrease to background levels by $4 \mathrm{~cm}$ depth, and that the majority of the REO is held in the top $0.5 \mathrm{~cm}$ of the soil. However, for $\mathrm{Nd}$, there is still a significant proportion held in the soil between 0.5 and $1.5 \mathrm{~cm}$ depth. As the depth of interaction is also an approximation of field interaction depths where soil topography is different, we compromised on a $1 \mathrm{~cm}$ depth of interaction for spray application. The target concentration used in this study was higher than that used in previously published studies, in order to provide a greater difference between tagged and untagged areas. 
After REO tagging, surface runoff generated during rainfall events between January 2008 and April 2008 was collected in tanks at the base of each hillslope length, with a portion of the runoff diverted to waste through a tipping bucket sample splitter to allow greater tank storage. The use of the sample splitter also enabled a pulse to be recorded on a datalogger for each 0.91 of runoff collected, from which the timing of hillslope runoff could be determined. Further information on the experimental design, runoff measurement, water sample collection and analysis of suspended sediment in runoff is available in the literature (Deasy et al., 2009b). For the tracing experiment, sediment samples were collected from the collection tanks at the base of each hillslope length and used for determination of REE concentrations. Loads and yields of eroded sediment were calculated for each hillslope length.

Sediment samples were dried, lightly ground and sieved to $<1 \mathrm{~mm}$. Subsamples were then used for extraction of REEs using an adapted USEPA method (Pryce, 2010), where $0.5 \mathrm{~g}$ samples were subjected to repeated heating using a heating block (SEAL BD50, SEAL Analytical, Fareham, Hampshire, UK) at $95^{\circ} \mathrm{C}$ with $20 \mathrm{ml} \mathrm{HNO}_{3}$ and approximately $10 \mathrm{ml}$ $\mathrm{H}_{2} \mathrm{O}_{2}$. Samples were then diluted to $100 \mathrm{ml}$ and filtered using $0.45 \mu \mathrm{m}$ Whatman filters before analysis. Extracted REE samples were analysed for $\mathrm{Pr}, \mathrm{Nd}, \mathrm{Sm}$ and $\mathrm{Gd}$ using ICPOES (Varian 725-ES, Varian Ltd. Oxford, UK) or ICP-MS (Thermo Elemental X7, Fisher Scientific UK Ltd., Loughborough, UK) for the elements where samples were below ICP-OES detection limits $\left(0.01-0.03 \mathrm{mg}^{-1}\right)$. Internal standards were used for analysis. All extractions and analyses were also undertaken on blank samples and on external soil standards (NCS DC73319, China National Analysis Centre for Iron \& Steel) for quality control.

Runoff events were defined as starting when the first tip was recorded in any hillslope tipping bucket in response to a rainfall trigger, and ended when the last runoff was recorded in any tipping bucket. Runoff $(\mathrm{mm})$, sediment loads $(\mathrm{kg})$, sediment yields $\left(\mathrm{kg} \mathrm{ha}^{-1}\right)$, and REE loads ( $\mathrm{mg}$ ) for each hillslope length were calculated for each monitored event after tracer application. Depletion rates $(\%)$ or ratio of total mass of depletion of an element to mass of the applied element for a hillslope, and estimated erosion rates $\left(\mathrm{kg} \mathrm{ha}^{-1}\right)$ using tracer proportions, were calculated for each hillslope area within tracer-tagged hillslope lengths (See Section S1 in Supplementary Material). Erosion rates were compared between different hillslope areas over time and for different cultivation treatments. Differences in erosion rates between treatments were analysed using GLM analysis in SPSS (PASW Statistics 17.0, SPSS Inc., Chicago, USA).

\section{Results and discussion}

\subsection{Results}

Three runoff events occurred in the winter and spring of 2008 after tagging of hillslope areas with REO tracers (Table 1). The three events monitored fit well within the range of rainfall events which occurred at Loddington in the study year (2007-2008), and in previous years (Table S1 and Fig. S2 in the Supplement), and can be considered to be representative of runoff occurring at the site under normal climatic conditions. The three rainfall events generated differing runoff responses (Fig. S3 in the Supplement). Runoff responses as recorded here at hillslope scale were generally much longer than would be expected for surface runoff, with low volumes of runoff sustained for many hours after rainfall had ended. In addition, runoff was not always continuous, and multiple peaks were recorded in some events. Event I was flashy in response to relatively high rainfall intensity. Event II had a long falling limb, in response to long duration moderate intensity rainfall. Event III was of low magnitude and long duration, as a result of lower rainfall intensities occurring over a longer period of time. Cumulative sediment losses from the four hillslope lengths used in the experiment averaged $20.0 \mathrm{~kg} \mathrm{ha}^{-1}$ for all four hillslope lengths over the three events.

Analysis of runoff and sediment transport characteristics for different cultivation types for three events monitored at Loddington during the rare earth oxide tracing experiment using GLM analysis indicates that there were no significant differences $(p<0.05)$ in sediment transport between the different soil cultivation types (Fig. S4, Supplement). As a result, erosion source areas for the four hillslope lengths were considered together in the remaining analysis. These averaged data for all tanks allow the general hillslope contributing area response to be shown. The variability shown in the results is likely to be due to differences in the erosion rates between the four different hillslope areas monitored, and between the storms monitored.

\subsection{Discussion}

\subsubsection{Tracer depletion rates}

Although tracer depletion rates for the Loddington hillslope appear to be very low (up to $0.4 \%$ over three events), these rates are consistent with REO recovery rates for a study in a small catchment in Ohio, USA, where depletion rates of only $0.83 \%$ to $8.19 \%$ were measured over 49 events (Kimoto et al., 2006).

The low depletion rates are consistent with the low erosion rates generally observed for UK soils. For example, average annual UK erosion rates of around $600 \mathrm{~kg} \mathrm{ha}^{-1}$ for clay soils, $1500 \mathrm{~kg} \mathrm{ha}^{-1}$ for silt soils, and $2500 \mathrm{~kg} \mathrm{ha}^{-1}$ for sand soils are reported in the literature (Evans, 1996). However, 
Table 1. Characteristics of events monitored during rare earth oxide tracer experiment. Data are averages for all four collection tanks sampled, with standard deviations shown in parentheses.

\begin{tabular}{lcccclll}
\hline Event & Date & $\begin{array}{c}\text { Rainfall } \\
(\mathrm{mm})\end{array}$ & $\begin{array}{c}\text { Peak Rainfall } \\
\left(\mathrm{mm} \mathrm{hr}^{-1}\right)\end{array}$ & $\begin{array}{c}\text { Runoff Duration } \\
(\mathrm{hr})\end{array}$ & $\begin{array}{l}\text { Runoff } \\
(\mathrm{mm})\end{array}$ & $\begin{array}{l}\text { SS } \\
\left(\mathrm{mg} \mathrm{l}^{-1}\right)\end{array}$ & $\begin{array}{l}\text { SS Yield } \\
\left(\mathrm{kg} \mathrm{ha}^{-1}\right)\end{array}$ \\
\hline I & 14 Feb 2008 & 25.6 & 19.2 & 95 & $0.7(0.4)$ & $1573(1034)$ & $13(14)$ \\
II & 19 Mar 2008 & 56 & 9.6 & 180 & $8.5(7.2)$ & $500(283)$ & $42(33)$ \\
III & 2 Apr 2008 & 21.8 & 9.6 & 227 & $0.8(0.5)$ & $893(416)$ & $5(1)$ \\
\hline
\end{tabular}

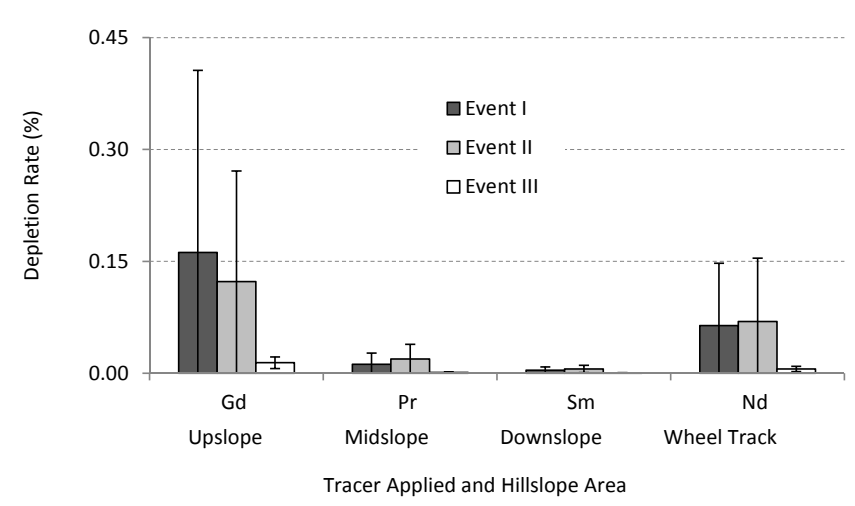

Fig. 2. Depletion rates of applied rare earth tracers for three events monitored at Loddington between January and April 2008 after tagging of four hillslope areas. Values are averages for four hillslope lengths, error bars are standard deviations.

these rates of erosion are still important, as even low rates of erosion can be a problem for sediment and nutrient transport, contributing significant levels of sediment and pollutants into receiving waters, and affecting water quality (Bilotta and Brazier, 2008). On-site erosion, although it leads in the longterm to soil degradation (Quinton et al., 2010), is not often a problem at this study site, while off-site erosion problems often are.

The low depletion rates also support the strong binding of REO tracers within hillslope soils demonstrated in laboratory studies (Zhang et al., 2001). A recent experiment (Polyakov et al., 2009) found that REO binding in the field was promoted by a number of rainfall events occurring after tagging of soils with the tracer, which did not generate runoff. Similarly, it is likely that the small rainfall event which occurred at Loddington in late January prior to event I, which was not enough to generate hillslope runoff (Fig. S2 in the Supplement), may have helped promote effective binding of the REO tracer after spraying, though it is possible some flushing of poorly incorporated REOs down the hillslope may have occurred in the first event.

Some of the applied tracer may also have been eroded and transported away from the hillslope via subsurface runoff pathways, for example through infiltration and field drainage. Recent research in artificially drained catchments, compar-

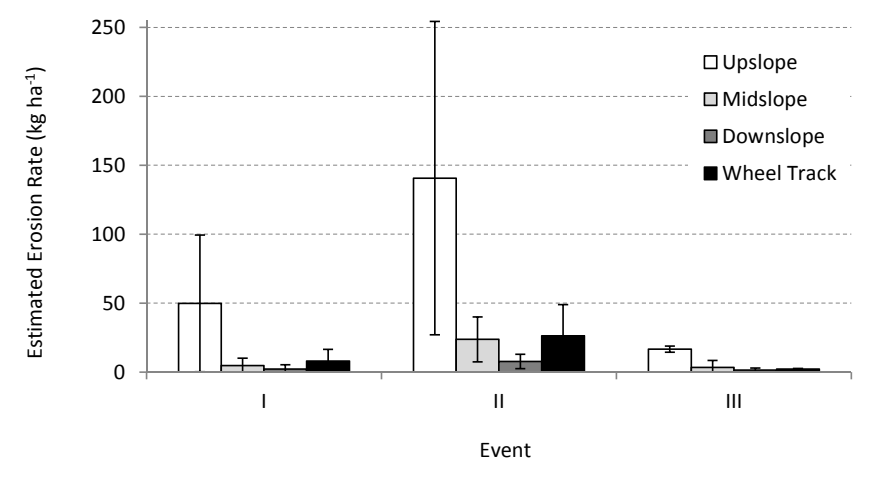

Fig. 3. Estimated erosion rates for hillslope areas tagged with rare earth oxides in three events at Loddington. Values are averages for four hillslope lengths, error bars are standard deviations.

ing surface and subsurface runoff pathways has demonstrated that subsurface runoff may account for a large proportion of the erosion occurring from a hillslope, particularly where surface runoff pathways largely correspond with tractor wheel tracks (Deasy et al., 2009a). Currently, there has been no consideration of this effect in the tracer literature.

\subsubsection{Erosion source areas and processes}

A previous study found that at the base of the Loddington hillslope, sediment could enter wheel tracks from unvegetated areas from as far away as $4 \mathrm{~m}$ (Stevens and Quinton, 2008). However, the results of this study suggest that sediment from the downslope area makes only a very small contribution to sediment eroded from the hillslope. The main source of sediment eroded from the hillslope in each event was the upslope area. This could be (i) because this hillslope area is more convex, leading to higher erosion rates studies using ${ }^{137} \mathrm{Cs}$ as a tracer have shown that the severity of erosion, and hence erosion sources, can depend on slope shape, with greatest loss on convex slopes (Montgomery et al., 1997), or (ii) because the upslope area acts as a runoff generation zone, with water and sediment transferred via the connection of ponded areas to the wheel tracks, which export eroded material efficiently to the base of the hillslope. It is also possible that erosion measured at the plot scale could be greater in the other hillslope areas, but due to connectivity 
and transport processes, measured erosion at hillslope length scale is actually greater from the top slope. The fact that the upslope area is the main sediment source at hillslope scale implies that the wheel tracks, the main route of runoff and sediment transport within the arable hillslope, are principally conduits for hillslope erosion, and were not highly active sites of erosion during the monitored events. This is consistent with the absence of observed rilling within the wheel tracks on the eroding plots during the study. Although sediment eroded from the midslope and downslope areas would involve smaller transport distances, these areas do not appear to be as well-connected to the base of the slope as the upslope area, which was slightly shallower and more convex, and where wheel tracks may be less incised.

The cohesive clay soils at Loddington are also likely to be a factor in determining erosion sources. For example, in a watershed study on coarse gravelly soils in Arizona, channel contributions were the dominant erosion source (Polyakov et al., 2009), while in a similar watershed study in Ohio on silt loam soils, channel slope elements were the most important sediment source (Polyakov et al., 2004; Kimoto et al., 2006). In the silt loam watershed, it was also found that sediment eroded from a source area either moves only a short distance to adjacent areas, or is transported through the channel system to the base of the slope, which fits with the pattern of transport at Loddington.

\subsubsection{Tracer application method}

Spraying tracers on to the soil surface in solution was an effective method for applying REO powders to soils. The calibrated sprayer resulted in even coverage of tracer over the soil surface, which can be seen visually (Fig. S1 in the Supplement). An even application rate was reliant on the ground coverage rate of the sprayer, but this was controlled by ensuring that all spraying was undertaken by the same user, and that up and downslope ground coverage rates were carefully timed. It was impractical to collect soil samples from within the sprayed area to determine field tracer application rates, as walking on the hillslope would remove applied REO solution and disturb the sprayed area, but the sprayer tests and application rate tests undertaken in the laboratory prior to the fieldwork ensured the spray rate was relatively even over the large areas sprayed. Because of the use of a calibrated sprayer, this application method can be considered an improvement on the methods used in previous studies where soil and tracer mixes were broadcast, either by hand (Polyakov et al., 2004, 2009) or using a fertiliser spreader (Stevens and Quinton, 2008), allowing the solution to bind to the soil surface at a known rate which was low enough not to generate ponding, runoff or preferential infiltration through macropores. In agricultural catchments in previous studies, broadcast tracers were incorporated by repeated disking and intense cultivation (Polyakov et al., 2004), which is likely to have influenced the high sediment yields measured in the first events, while others have avoided this problem by not incorporating tracers (Stevens and Quinton, 2008), which may have resulted in a layer of tagged material on the soil surface being readily available for entrainment. In both experiments, the necessary experimental preparation is likely to have influenced the results of the experiment. The surface spraying method presented here offers a workable technique which has a limited effect on the in-situ soil and allows the results of the experiment to represent naturally occurring erosion processes.

Previous studies exploring the use of REOs as sediment tracers at hillslope scale (Polyakov et al., 2004, 2009; Kimoto et al., 2006) have drawn attention to the issue of tracer dilution from untagged hillslope areas. This is particularly of concern where erosion depths occur which are greater than the tagging depth. However, on gently eroding hillslopes, such as those in the UK, where average erosion rates equate to soil lowering rates of around $0.4-1.8 \mathrm{~mm} \mathrm{year}^{-1}$ (from Evans (1996), assuming typical soil bulk density characteristics from Ruehlmann and Korschens, 2009), a tracer incorporation depth of $1 \mathrm{~cm}$ is likely to be appropriate and would allow sediment movement to be traced over periods of weeks to years. Where localized rilling and gullying occur, then any REO tracer method where tracer is incorporated over whole hillslope areas may result in poor estimations of relative erosion rates, although it could still be used to indicate source areas.

\subsubsection{Implications and future directions}

These results suggest that under typical UK event conditions, on arable hillslopes, soil is principally eroded from gently sloping convex hillslope areas, which may not be closest to the base of the slope, where ponded areas are connected to preferential runoff pathways. For cohesive soils, erosion may not occur within the preferential pathways in all events, and sediment losses under typical event conditions are likely to be detachment limited, with sediment sources on arable hillslopes likely to be exhausted through a rainfall event. Mitigation treatments for sediment losses from arable hillslopes should therefore focus on methodologies for trapping mobile sediments within wheel track areas through increasing surface roughness or reducing runoff transport through ponding and infiltration. The sprayer application method presented here has been shown to be effective on a temperate arable hillslope, however, this application method could also be used for studies to be undertaken at other research sites, including hillslope-scale studies on temperate grassland, rangeland and semi-arid areas where rapid application of large volumes of tracer is needed, and disturbance of the soil surface is undesirable or inappropriate. 


\section{Conclusions}

Understanding sediment sources is essential to enable more effective targeting of in-field mitigation approaches to reduce diffuse pollution from agricultural land, but a lack of appropriate sediment tracing techniques limit our ability to measure source areas and rates of erosion at small temporal and spatial scales. A method of applying REO tracers directly to hillslopes causing minimal soil surface disturbance was developed here and tested in the field. Runoff, sediments and REEs lost from four arable hillslope lengths at a site in the UK with clay soils were monitored from three rainfall events after tracer application. The results from the UK field experiment suggest that REO tracers can be applied to large hillslope areas using surface spraying of powders in suspension, in order to trace source areas for sediments eroded from hillslopes in surface runoff. Measured erosion rates were low, reflecting the typical event conditions occurring at the site, and less than $1 \%$ of the applied REO tracers were recovered, which is consistent with the results of comparable studies. Tracer recovery was, however, able to indicate the relative importance of different hillslope sediment source areas, which were found to be consistent between events. The upslope area was most important for erosion, which is likely to be due to better connectivity between this area and the tractor wheel tracks. This also suggests that the wheel tracks were principally conduits for sediment transport, and not highly active sites of erosion. Mitigation treatments for sediment losses from arable hillslopes should therefore focus on methodologies for trapping mobile sediments within wheel track areas through increasing surface roughness or reducing the connectivity of sediment generating areas.

\section{Supplementary material related to this article is available online at: http://www.solid-earth.net/1/111/2010/ se-1-111-2010-supplement.pdf.}

Acknowledgements. This work was funded by the UK Department for Environment, Food and Rural Affairs, under contract PE0206. We thank the Allerton project, Game \& Wildlife Conservation Trust for access to the field site, and Brenda Cookson at Lancaster University for support during the experimental work.

Edited by: A. Cerdà

\section{References}

Bilotta, G. S. and Brazier R. E.: Understanding the influence of suspended solids on water quality and aquatic biota, Water Res., 42(12) 2849-2861, 2008.

Collins, A. L. and Walling, D. E.: Documenting catchment suspended sediment sources: Problems, approaches and prospects, Prog. Phys. Geog., 28, 159-196, 2004.
Croke, J., Hairsine, P., and Fogarty, P.: Sediment transport, redistribution and storage on logged forest hillslopes in south-eastern Australia, Hydrol. Process., 13, 2705-2720, 1999.

Deasy, C., Brazier, R. E., Heathwaite, A. L., and Hodgkinson, R.: Pathways of runoff and sediment transfer in small agricultural catchments, Hydrol. Process., 23(9), 1349-1358, 2009a.

Deasy, C., Quinton, J. N., Silgram, M., Bailey, A. P., Jackson, B., and Stevens, C. J.: Mitigation options for sediment and phosphorus loss from winter-sown arable crops, J. Environ. Qual., 38(5), 2121-2130, 2009b.

Evans, R.: Soil erosion and its impacts in England and Wales, in, Friends of the Earth Trust, London, 1996.

Fransen, P. J. B, Phillips, C. J, and Fahey, B. D: Forest road erosion in New Zealand: overview, Earth Surf. Proc. Land., 26(2), 165$174,2001$.

Gruszowski, K. E., Foster, I. D. L., Lees J. A., and Charlesworth S. M.: Sediment sources and transport pathways in a rural catchment, Herefordshire, UK, Hydrol. Process., 17, 2665-2681, 2003.

Haygarth, P. M. and Jarvis, S. C.: Transfer of phosphorus from agricultural soils, Adv. Agron., 66, 195-249, 1999.

Kimoto, A., Nearing, M. A., Shipitalo, M. J., and Polyakov, V. O.: Multi-year tracking of sediment sources in a small agricultural watershed using rare earth elements, Earth Surf. Proc. Land., 31, 1763-1774, 2006.

Lei, T. W., Zhang, Q. W., Zhao, J., and Nearing, M. A.: Tracing sediment dynamics and sources in eroding rills with rare earth elements, Eur. J. Soil Sci., 57, 287-294, 2006.

Li, Y. X., Tullberg, J. N., and Freebairn, D. M.: Wheel traffic and tillage effects on runoff and crop yield, Soil and Tillage Research, 97, 282-292, 2007.

Liu, P.-L., Tian, J.-L., Zhou, P.-H., Yang, M.-Y., and Shi, H.: Stable rare earth element tracers to evaluate soil erosion, Soil and Tillage Research, 76, 147-155, 2004.

Luce, C. H. and Black, T. A.: Spatial and Temporal Patterns in Erosion from Forest Roads, in: Influence of Urban and Forest Land Uses on the Hydrologic-Geomorphic Responses of Watersheds, edited by: Wigmosta, M. S. and Burges, S. J., Water Resources Monographs, American Geophysical Union, Washington, D.C., 165-178, 2001.

MacDonald L. H., Anderson D. M., and Dietrich W. E.: Paradise threatened: Land use and erosion on St John, US Virgin Islands, Environmental Management, 21(6), 851-863, 1997.

Montgomery, D. R.: Soil erosion and agricultural sustainability, P. Natl. A. Sci., 104(33), 13268-13272, 2007.

Montgomery, J. A., Busacca, A. J., Frazier, B. E., and McCool, D. K.: Evaluating soil movement using cesium-137 and the revised universal soil loss equation, Soil Sci. Soc. Am. J., 61, 571-579, 1997.

Olmez, I., Pink, F. X., and Wheatcroft, R. A.: New particle-labeling technique for use in biological and physical sediment transport studies, Environ. Sci. Technol., 28, 1487-1490, 1994.

Owens, P. N., Batalla, R. J., Collins, A. J., Gomez, B., Hicks, D. M., Horowitz, A. J., Kondolf, G. M., Marden, M., Page, M. J., Peacock, D. H., Petticrew, E. L., Salomons, W., and Trustrum, N. A.: Fine-grained sediment in river systems: Environmental significance and management issues, River Res. Appl., 21, 693$717,2005$.

Polyakov, V. O. and Nearing, M. A.: Rare earth element oxides for 
tracing sediment movement, Catena, 55, 255-276, 2004.

Polyakov, V. O., Nearing, M. A., and Shipitalo, M. J.: Tracking sediment redistribution in a small watershed: Implications for agrolandscape evolution, Earth Surf. Proc. Land., 29, 1275-1291, 2004.

Polyakov, V. O., Kimoto, A., Nearing, M. A., and Nichols, M. H.: Tracing sediment movement on a semiarid watershed using rare earth elements, Soil Sci. Soc. Am. J., 73, 1559-1565, 2009.

Pryce, O: Development of Environmental Tracers for Phosphorus and Sediments, $\mathrm{PhD}$ Thesis, Lancaster University, Lancaster, UK, 2010.

Quinton, J. N., Govers, G., Van Oost, K., and Bardgett, R. D.: The impact of agricultural soil erosion on biogeochemical cycling, Nat. Geosci., 3(5), 311-314, 2010.

Ramos-Scharrón, C. E. and MacDonald, L. H.: Measurement and prediction of sediment production from unpaved roads, St John, US Virgin Islands, Earth Surf. Proc. Land., 30(10), 1283-1304, 2005.

Ruehlmann, J. and Korschens, M.: Calculating the effect of soil organic matter concentration on soil bulk density, Soil Sci. Soc. Am. J., 73, 876-885, 2009.

Sharpley, A. N., Chapra, S. C., Wedepohl, R., Sims, J. T., Daniel, T. C., and Reddy, K. R.: Managing agricultural phosphorus for protection of surface waters: Issues and options, J. Environ. Qual., 23, 437-451, 1994.
Silgram, M., Jackson D. R., Bailey, A., Quinton J. N., and Stevens, C.: Hillslope scale surface runoff, sediment and nutrient losses associated with tramline wheelings, Earth Surf. Proc. Land., 35(6), 699-706, 2010.

Stevens, C. J. and Quinton, J. N.: Investigating source areas of eroded sediments transported in concentrated overland flow using rare earth element tracers, Catena, 74, 31-36, 2008.

Tullberg, J. N., Yule, D. F., and McGarry, D.: Controlled traffic farming-from research to adoption in australia, Soil and Tillage Research, 97, 272-281, 2007.

Ventura, E., Nearing, M. A., and Norton, L. D.: Developing a magnetic tracer to study soil erosion, Catena, 43, 277-291, 2001.

Withers, P. J. A., Hodgkinson, R. A., Bates, A., and Withers, C. M.: Some effects of tramlines on surface runoff, sediment and phosphorus mobilization on an erosion-prone soil, Soil Use Manage., 22, 245-255, 2006.

Zhang, X. C., Friedrich, J. M., Nearing, M. A., and Norton, L. D.: Potential use of rare earth oxides as tracers for soil erosion and aggregation studies, Soil Sci. Soc. Am. J., 65, 1508-1515, 2001.

Zhang, X. C., Nearing, M. A., Polyakov, V. O., and Friedrich, J. M.: Using rare-earth oxide tracers for studying soil erosion dynamics, Soil Sci. Soc. Am. J., 67, 279-288, 2003. 